ORIGINAL ARTICLE

\title{
Coblation Tonsillectomy Versus Blunt Dissectomy Tonsillectomy in Children
}

\author{
*MA Matin ${ }^{1}$, MA Chowdhury ${ }^{2}$, ME Haque $^{3}$, MN Islam $^{4}$, T Shamim $^{5}$, MA Muqeet $^{6}$, MR Ali $^{7}$ \\ ${ }^{* 1}$ Dr. M A Matin, Associate Professor, ENT \& HNS, Rajshahi Medical College, Bangladesh \\ ${ }^{2}$ Prof. Dr. M Alamgir Chowdhury. Professor of ENT \& HNS, Anowar khan Modern Medical College, Dhaka \\ ${ }^{3}$ Dr. Md Enamul Haque, Asstt. Professor ENT, Rajshahi Medical College \\ ${ }^{4}$ Dr. Md Nurul Islam, Medical Officer, ENT Department, Shahid Ziaur Rahman Medical College, Bogra \\ ${ }^{5}$ Dr. Tahsina Shamim. Consultant, MCH Centre, Rajshahi \\ ${ }^{6}$ Dr. $M$ A Muqeet, Associate Prof, BSMMU \\ ${ }^{7}$ Dr. Md Rowshan Ali, Consultant Anaesthetist, Bogra Diabetic Hospital
}

*Corresponding Author

\begin{abstract}
Tonsillectomy is one of the most common surgical procedure performed world wide by the ENT Surgeons.Various methods of tonsillectomy have been practiced over the century aimed at reducing or eliminating intraoperative and postoperative morbidity. Coblation tonsillectomy is a recently introduced surgical technique. Tonsillectomy over blunt dissection tonsillectomy in respect of operative time, intraoperative blood loss, postoperative pain, rate of healing of tonsillar fossa and other postoperative complications. This prospective randomized study was done at Maleka Nursing Home, Bogra and Bangladesh ENT Hospital, Dhaka for 36 months from 1st January 2008 to 31 December 2010. 200 children were divided into two groups of equal number. In one group, the tonsillectomy performed by Coblation method and in the other group the tonsillectomy Age ranged from 3-12 years with mean age 5.6 in coblation group and 4-14 years with mean age 7.2 in dissection group. Number of male patients were slightly more than female with male female ratio was $3: 2$ in coblation group and 3.7:2 in dissection group. Operative time and amount of blood loss is significantly reduced in the coblation group (10-25 min, mean $12 \mathrm{~min}$ in coblation group, 18-35 min, mean $25 \mathrm{~min}$ in dissection group. Tonsillectomy by using coblation have shown less intraoperative bleeding (5ml-100 ml, mean $15 \mathrm{ml}$ compared with 50-230 ml, mean $65 \mathrm{ml}$ in dissection method). During post operative follow-up on day 8, children of coblation group experienced mild to moderate pain with maximum pain on day 2 and no pain on day 8. On the other hand dissection group experienced moderate to severe pain with maximum pain on day 4 and little or no pain on day 8.Children of coblation group returned to normal diet on day 3 and children of dissection group on day 8.On 8th post operative day, coblation group showed smooth healing without any granulation tissue in tonsillar fossa whereas granulation tissue is observed in dissection group. No major complications were noted in any group except one secondary haemorrhage in dissection group. Coblation tonsillectectomy offers less operative time, minimum blood loss, less post operative pain, early return to normal diet and rapid healing of tonsillar fossa.
\end{abstract}

Key Words: Tonsillectomy, Blunt dissection, Coblation, Radiofrequency

\section{Introduction}

Tonsillectomy is the surgical procedure of removing the tonsils and it is one of the most common surgical procedures performed worldwide $^{1}$. Since the first tonsil removal performed by Celsus in $30 \mathrm{BC}^{2}$, multiple surgical techniques have been described and

diverse instruments have been evolved for this purpose $^{3}$. It is recommended in patients with chronic tonsillitis, recurrent attack of acute tonsillitis, peritonsillar abscess, sleep apnoea syndrome and unilateral tonsillar hypertrophy with suspicion of malignancy, TB or any other

AKMMC J 2013: 4(1): 25-29 
Coblation Tonsillectomy Versus Blunt Dissectomy

growth ${ }^{4,5}$. At the beginning of the 21 st century dissection tonsillectomy is more often used than tonsillotomy ${ }^{6,7}$. In the 1960 s and1970s, one to 2 million tonsillectomies, adenoidectomies or combined procedures were performed annually in the United States $8,9,10$. The most important complications of tonsillectomy are the operative and post operative haemorrhage and severe post operative pain resulting in odynophagia ${ }^{8}$. Described methods of tonsillectomy include blunt dissection, guillotine excision, cryosurgery, monopolar and bipolar diathermy dissection, ultrasonic scalpel, laser and recently introduced coblation assisted tonsillectomy ${ }^{7,11}$. However, the dissection technique has remained the standard procedure for tonsillectomy for many years till now. The surgical technique of coblation tonsillectomy is based on dissection of tonsil in the relatively bloodless tonsillarmuscular plane, using an Arthrocare Evac 70 plasma wand (Fig 1) ${ }^{7}$. The operating principle of coblation is similar to bipolar diathermy or electrosurgery. In both methods, an alternative current passing between the active electrodes at the tip of the device produces destruction of the target tissue adjacent to the electrodes. In bipolar diathermy, direct contact between electrodes and tissue produces local temperature s of 400 degree $C$ to 600 degree $C$ resulting in heating of intracellular contents and subsequent vaporization of the cell ${ }^{12}$. In contrast coblation must fill the physical space between the electrodes with a medium rich in sodium (eg, isotonic saline or saline gel) By coblation the medium is dissociated into the free sodium ions which are responsible for the destruction of itrcellular bomds, resulting in tissue destruction. The reaction is achived at temperatures between 60 degree $\mathrm{c}$ to 70 degree $\mathrm{C}$ with minimal collateral thermal tissue damage. Also the presence of cool irrigating isotonic saline helps to limit the amount of heat delivered to the surrounding structures $7,13,14$.

\section{Materials and Methods}

This is a prospective randomized study to compare the result of coblation assisted tonsillectomy with those of conventional dissection technique with regards to the operative time, intra-operative bleeding, postoperative bleeding and other related complications. This prospective randomized study was done at Maleka Nursing Home, a private General Hospital at Bogra and Banglasesh ENT Hospital from 1st January2008 to 31 december 2011. 200 patients were divided into two groups of equal number. In one group, the tonsillectomy performed by Coblation and in the other group the tonsillectomy performed by conventional dissection technique. The patients were randomized to either the coblation group or the conventional dissection group of equal number. All operations were done under general anaesthesia. All patients were kept one day at hospital. In coblation Evac 70 plasma wand was used for dissection and haemostasis and power was set at 6 . In dissection group blunt tonsillar dissector was used to dissect the tonsilar tissue from the tonsilar bed and the lower pole was clamped using Wilson forceps and silk ligature was used. Hemostasis was secured by suture ligation or by bipolar diathermy. Surgical time was measured from the insertion of Boyle-Davis mouth gag to the final haemostasis and removal of mouth gag. Intraoperative blood loss was measured by weighing the tonsil swab before and after tonsillectomy and by measuring the amount in the suction bottle. All patients were given perioperative antibiotic (cephradine) and post operative analgesics (paracetamol and diclofenac if needed) Postoperatively, pain scores were charted from day one to day 8 using standardized visual analogue scale 1-10, mild (0-3), moderate (4-6), severe (710). The parents were also asked to keep records of any complications. Patients were reviewed in the clinic on 8th post operative day.

\section{Results}

Of the 200 patients recruited in this study, 100 patients were in the coblation group and another 100 patients were in the convensional dissection group. Male outnumbered female in both groups with the ratio of $60: 40$ and $65: 35$ in the coblation and conventional group respectively. (Table I) The mean age was 5.6 years (range, 312 y) for coblation group and 7.2 years for 
Matin MA, Chowdhury MA, Haque ME et al

dissection group (range, 4-14 y) (Table II). The mean operative time for coblation group was 12 min.(range, 10-25 min.) and $25 \mathrm{~min}$. for dissection group (range, 18-35 min)(Table III). Mean intraoperative bleeding for coblation group was $15 \mathrm{~mL}$ (range, 5-100 mL) compared with $65 \mathrm{~mL}$ for dissection group (range, 50-230 $\mathrm{mL}$ ). (Table IV) . The pain scores (VAS) and duration of pain in both groups were compared.(Table V) Patients experienced mild to moderate pain in coblation group and moderate to severe pain in dissection group in first 24-96 hours. Both grops showed an initial rise in mean pain scores with day 2 being the most painful in the coblation group, day 4 for the dissection group and no pain on day 8 in coblation group whereas still there was mild pain on day 8 in dissection group. A noticeable difference was found in the day of return to normal diet -day 4 for coblation group compared with day 8 for dissection group(Table VI) On 8th post operative day smooth tonsillar fossa with good healing and no granulation tissue observed in coblation group but considerable slough or granulation tissue present in the dissection group (Table VII) There were no episodes of primary or secondary haemorrhage in coblation group where as one secondary haemorrhage experienced in dissection group which was controlled by conservatively(Table VIII).

Table I: Distribution of patients according to sex $(\mathrm{N}-200)$

\begin{tabular}{lcc}
\hline Sex & Coblation group & Dissection group \\
\hline Male & 60 & 65 \\
Female & 40 & 35 \\
Male: Female & $3: 2$ & $3.7: 2$ \\
\hline
\end{tabular}

Table II: Distribution of patients according to age(N-200)

\begin{tabular}{lcc}
\hline Age & Coblation group & Dissection group \\
\hline Min. & 3 & 4 \\
Max. & 12 & 14 \\
Mean & 5.6 & 7.2 \\
\hline
\end{tabular}

Table III: Operative time in minutes(N-200)

\begin{tabular}{lcc}
\hline Time & Coblation group & Dissection group \\
\hline Min. & 10 & 18 \\
Max. & 25 & 35 \\
Mean. & 12 & 25 \\
\hline
\end{tabular}

Table IV: Intra operative blood loss in $\mathrm{mL}(\mathrm{N}-200)$

Amount of loss in mL Coblation group Dissection group

\begin{tabular}{lll}
\hline Min. & 5 & 50 \\
Max. & 80 & 230 \\
Mean. & 10 & 65 \\
\hline
\end{tabular}

Table V: Post operative pain (No 200)

\begin{tabular}{lll}
\hline Time & Coblation group & Dissection group \\
First 24-48 hrs & Mild to moderate & Moderate to severe \\
Day 2 & Maximum pain & \\
Day 4 & & Maximum pain \\
Day 8 & No pain & Still mild pain \\
\hline
\end{tabular}

Table VI: Day of return to normal $\operatorname{diet}(\mathrm{N}-200)$

\begin{tabular}{lll}
\hline Coblation & group & Day 3 \\
Dissection & group & Day 8
\end{tabular}

Table VII: Tonsillar fossa on 8th POD(N-200)

Coblation group Smooth healing, no granulation tissue

Dissection group Still there is some slough/ granulation tissue

Table VIII: Rate of complications(N-200)

\begin{tabular}{ll}
\hline Coblation group & No reactionary/sec. haemorrhage \\
Dissection group & One sec. haemorrhage
\end{tabular}

\section{Discussion}

Coblation tonsillectomy is a recently introduced dissecting technique with few reports in the literature 6,14,15.In Bangladesh the author has been using this technique since 2005. Only one paper of coblation tonsillectomy was published in BMA journal 11 Blackburn and Ribble valley Health Authority possess the largest series of 
coblation tonsillectomies in the United Kingdom and probably one of the largest in the world with nearly 850 operations ${ }^{1}$. Coblation is a new technique in the soft tissue surgery 16 . Recently the use of this new technique in the treatment of snoring, nasal congestion and sleep apnoea has received considerable research interest 15,16 . As for the department of ENT, tonsillectomy is the most frequently operative procedure performed and conventional blunt dissection technique has been and continue to be considered a most common and standard method of tonsillectomy. There is no consensus on the optimum method of performing tonsillectomy. Various methods have been described which are frequently compared and discussed in otolaryngology literature17. In most studies, most of the new techniques used are usually compare to the standard blunt dissection technique. The value of a new technique must be judged by the results concerning intraoperative and postoperative morbidity and complications. The most common postoperative concerns following tonsillectomy are hemorrhage and pain. Postoperative pain is the most significant subjective symptoms as far as patient is concerned.

In this study, operating time for tonsillectomy is determined by the duration, which the bleeding is secured. Thus, the time taken to control the bleeding will influence the operating time as well as the blood loss. In our study, the blood loss was significantly reduced and operative time was significantly shorter in the coblation group. Postoperative pain should be minimized not just for the patients comfort but also because it may impair swallowing with a risk of dehydration, infection and secondary haemorrhage. Hot electrosurgery and laser tonsillectomy has been reported to cause more severe postoperative pain than conventional blunt dissection technique ${ }^{18,19}$. In our study, we found that children of coblation group experienced mild to moderate pain with maximum on day 2 and no pain on day 8 in comparison to dissection group where children experienced moderate to severe pain with maximum pain on day 4 and mild pain on day ${ }^{8}$. It is worth noted that there were no major complications observed in this study apart from one secondary haemorrhage in dissection group and all patients from both groups did not require second general anesthesia for primary or secondary haemorrhage.

\section{Conclusion}

This study was designed purely to assess new method coblation with classical dissection method regarding operative time, amount of blood loss, post operative pain, rate of healing of tonsillar fossa, return to normal diet and post operative complications. Very significant benefits have been observed in all of these respects when using this new method. This benefit justifies further evaluation of this method.

\section{References}

1. Belloso A, Chidambaram A, Morar P, et al. Coblation tonsillectomy versus dissection tonsillectomy, post operative haemorrhage. Laryngoscope 2003; 113(11): 2010-13.

2. Curtain J M. The history of tonsil and adenoid surgery. Otolaryngol Clin North Am 1987; 20: 41519.

3. Younis R T, Lazar R H. History and current practice of tonsillectomy. Laryngoscope 2002; 112:3-5.

4. Paradise JL. Tonsillectomy and Adenotonsillectomy for recurrent throat infection in moderately affected children. Paediatrics 2002; 110(1): 7-9

5. Paradise JL, Bluestone CD, Bachman RZ. Efficacy of tonsillectomy for recurrent throat infection in severely affected children-results of parallel randomized and nonrandomized clinical trial. N.Eng. J. Med. 1984; 310: 674-83.

6. Lloyd Faulconbridge R V, Fowler J. Traditional Tonsillectomy, comparative audit of tonsillectomy. Clin Otolaryngol 2000; 25: 100-17.

7. Black I, Paloheimo M, Ylikoski J. Traditional tonsillectomy compared with bipolar radiofrequency thermal ablation tonsillectomy in adults, a pilot study. Arch Otolaryngol Head Neck Surg 2001; 127: 1106-12. 
8. Khan MF, Iqbal J, Raza N, et al. Diode laser tonsillectomy a comparison with conventional technique. Pakistan Journal of Otolaryngology 2002; 26: 30-31.

9. Faigel HC. Tonsillectomy: a bloody mess. Clin Pediatr (Phil) 1966; 5: 652-53.

10. Gibb AC. Unusual complications of tonsil and adenoid removal. J Laryngol Otol 1969; 83: 1159-174.

11. Matin M A. Coblation tonsillectomy versus blunt dissection tonsillectomy, study of 120 cases. Bangladesh Med J 2006; 35(1): 18-20.

12. Temple R H, Timms M S. Paediatric coblation tonsillectomy. Int J Pediatr Otorhinolaryngol 2001; 61: 195-98.

13. Timms M S, Temple R H. Coblation tonsillectomy, a double blind randomized controlled study. J Laryngol Otol 2002; 116: 450-52.

14. Plant T L. Radiofrequency treatment of tonsillar hypertrophy. Laryngoscope 2002; 112: 20-22.
15. Madani M. Radiofrequency somnoplasty, a new treatment for snoring and sleep apnoea. Int J Oral Maxillofac Surg 1999; 1: 108-9.

16. Handler SD, Miller L, Richmond KH, et al. Posttonsillectomy haemorrhage: incidence, prevention and management. Laryngoscope 1986; 96: 1243247.

17. Leach J, Manning S, Schaefer S. Comparison of two methods of tonsillectomy. Laryngoscope 1993; 103: 619- 22.

18. Auf I, Osborne JE, Sparkes C, et al. Is the KTP laser effective in tonsillectomy? Clin Otolarygol 1997; 22: 145-46.

19. Matin M A, Chowdhury M A. Diode laser versus blunt dissection tonsillectomy. Bangladesh $\mathrm{J}$ Otorhinolaryngol 2012; 18(2): 114-18. 